\title{
Overweight and Cystic Fibrosis: An Unexpected Challenge
}

\author{
Megan Gabel ${ }^{1}$, Claudia Fox ${ }^{2}$, Rachel Grimes ${ }^{3}$, John Lowman ${ }^{4}$, Catherine McDonald ${ }^{5}$, \\ Virginia Stallings ${ }^{6}$, and Suzanne Michel $^{7}$ \\ ${ }^{1}$ University of Rochester Medical Center \\ ${ }^{2}$ University of Minnesota System \\ ${ }^{3}$ Cook Children's Medical Center \\ ${ }^{4}$ University of Alabama at Birmingham HCOP \\ ${ }^{5}$ Primary Children's Hospital \\ ${ }^{6}$ The Children's Hospital of Philadelphia \\ ${ }^{7}$ Medical University of South Carolina
}

September 24, 2021

\begin{abstract}
Achieving a healthy weight balance has been a central focus of care for people who have cystic fibrosis (CF). Over the years, the emphasis has primarily been on promoting weight gain in order to optimize pulmonary outcomes. With continued improvements in $\mathrm{CF}$ care, including highly effective $\mathrm{CF}$ modulator available for many people, the CF community is now experiencing a new challenge: addressing the concern that some people are gaining weight excessively. While at this time, we do not know to what extent overweight and obesity will affect health outcomes for people with CF, it is likely that excessive weight gain may have negative health impacts similar to those seen in the general population. In this paper, we review the history of nutritional guidelines for people with $\mathrm{CF}$, as well as more recent trends toward overweight and obesity for some. A multidisciplinary approach is needed to collaboratively start the oftentimes difficult conversation regarding excessive weight gain, and to identify resources to help people achieve and maintain a healthy weight through diet, exercise, and behavioral modification.
\end{abstract}

\section{Hosted file}

Cystic Fibrosis Overweight 8_11_21-MG.docx available at https://authorea.com/users/435893/ articles/538614-overweight-and-cystic-fibrosis-an-unexpected-challenge

\section{Hosted file}

CF weight management tables 8_12_21 MG.docx available at https://authorea.com/users/435893/ articles/538614-overweight-and-cystic-fibrosis-an-unexpected-challenge 